\title{
Microhistoria de una sociedad microscópica: aproximación a la misión jesuita en el Alto Napo (Ecuador), 1870-1896
}

\author{
Jaime Moreno TEJADA \\ Universidad de Khon Kaen, Tailandia \\ jaimte@kku.ac.th
}

Recepción: 18 de enero de 2011 / Revisión: 21 de septiembre de 2011

Aceptación: 13 de octubre de 2011 / Publicación: diciembre de 2012

\section{RESUMEN}

El presente estudio representa una reevaluación de la historia jesuita en el Alto Napo ecuatoriano a finales del siglo XIX y principios del XX. Se trata de una mirada micro-histórica a las relaciones socioeconómicas existentes entre religiosos, indígenas, mercaderes y autoridades civiles, en una época de grandes transformaciones - tanto en Ecuador como en la Amazonía. El artículo está basado en fuentes primarias, publicadas y de archivo, muchas de las cuales no han sido estudiadas hasta la fecha.

Palabras clave: jesuitas, Amazonia, Ecuador, Alto Napo, Oriente, microhistoria, Napo Runa, caucho, Ecuador, siglo XIX.

\section{Microhistory of a Microscopic Society: An Approximation to the Jesuit Mission of the Upper Napo (Ecuador), 1870-1896}

\begin{abstract}
This study represents a re-evaluation of the Jesuit experience in the Upper Napo of Ecuador at the turn of the twentieth century. The article is a micro-historical approach to the links that existed between Jesuits, Indians, merchants and civil authorities, in a time of great transformations -both in Ecuador and in the Amazon. This research is based on primary sources, published as well as archival, many of which have not been studied to this day.
\end{abstract}

Key words: Jesuits, Amazon, Ecuador, Upper Napo, Oriente, Microhistory, Napo Runa, Rubber, Ecuador, $19^{\text {th }}$ Century.

Sumario: 1. Introducción. 2. Estructura de la misión: misioneros e indios. 3. Los eventos: rumor, política y caída de la misión. 4. Conclusiones. 5. Referencias bibliográficas. 


\section{INTRODUCCIÓN}

El trabajo misional en el siglo XIX es uno de campos de estudio menos conocidos entre los historiadores de frontera $\mathrm{y}$, en particular, entre aquéllos que se dedican a las investigaciones amazónicas. Ecuador no ha escapado de este olvido. La misión jesuita que se estableció en el Oriente entre 1869 y 1896 ha recibido escasa atención ${ }^{1}$. Esto se debe en parte a la relativa pobreza documental y al -hasta la fecha al menosdifícil acceso a algunos de los archivos más importantes ${ }^{2}$. El presente estudio constituye una aproximación a la estructura y dinámica de la misión en el Alto Napo, una región intermedia entre el altiplano andino y la alta amazonía. Los historiadores de esta región han favorecido el análisis sociológico, las perspectivas macro-analíticas y/o las visiones "centralizadas" (por ejemplo, desde el punto de vista de la legislación quiteña) de la región amazónica ${ }^{3}$. Este trabajo se decanta por el micro-análisis de una sociedad de frontera: de población escasa y dispersa, de instituciones y cultura material paupérrimas. Es decir, una sociedad microscópica, como la del Alto Napo en las últimas décadas del siglo XIX. Una perspectiva micro-histórica es recomendable, además, para lograr una integración con las corrientes actuales de investigación amazónica ${ }^{4}$. El artículo está dividido en dos bloques: el primero trata de la estructura de la misión en el marco de las relaciones entre jesuitas e indios; el segundo coloca la misión en un contexto más amplio y analiza, de forma cronológica, el papel de los diferentes agentes (gobierno central y local, comerciantes, indígenas, misioneros) en el progreso y caída de la misión.

\subsection{Nota introductoria: la llegada de los jesuitas a Ecuador}

Las circunstancias que condujeron a la entrada de los jesuitas al Oriente ecuatoriano tienen que ver con las acciones del devoto y conservador presidente Gabriel García Moreno (1860-1865, 1869-1875) pero también con el proceso de formación del estado-nación y con la situación específica de la región amazónica. Después de la expulsión de los territorios americanos en 1767, desde la restauración en 1814, y a lo largo del siglo XIX, la Compañía de Jesús fue víctima de la nueva realidad política, es decir, la alternancia de partidos y las disensiones ideológicas entre liberales y conservadores. En Ecuador, el caos político y social de finales de la década de 1850 fue favorable a los intereses jesuitas: el ultra conservador Gabriel García Moreno

\footnotetext{
1 Varias son las historias descriptivas, siempre escritas por misioneros: JoUANEN, 1977; una visión más general en GARCíA, 1985; y la inédita obra, VASCÓNEZ, 1941.

2 El archivo jesuita de Cotocollao permanecía cerrado durante el curso de esta investigación. Esta falta fue parcialmente corregida con los documentos obtenidos en el Archivum Romanum Societatis Iesu (en adelante ARSI) en Roma.

3 Son pioneros y relativamente interesantes los trabajos del Taller de Estudios e Investigaciones AndinoAmazónicas. Por ejemplo, la obra de García, 1995. El estudio etnohistórico fundamental es Muratorio, 1991. Véase también MoReno Tejada, 2009.

4 La historia cultural es un excelente punto de partida para entender la necesidad de incorporar microanálisis al estudio de la región amazónica. Ver SLATER, 2002.
} 
emergió como presidente y la Compañía de Jesús fue readmitida en el Ecuador ${ }^{5}$. En 1866 Monseñor Vicente Pastor, de la Diócesis de Guayaquil, fue enviado al Oriente en un viaje de reconocimiento ${ }^{6}$. Finalmente, en Noviembre de 1869, al inicio del segundo gobierno de García Moreno (1869-75), se firmó el contrato para el establecimiento de la misión jesuita en el Oriente ${ }^{7}$. García Moreno tenía en mente un plan de modernización e integración nacional, que incluía un ambicioso proyecto educativo. Los jesuitas llegaron a Ecuador, pues, para hacerse cargo de la educación secundaria y superior. Una vez establecidos en Quito y otras ciudades, fueron invitados a trasladarse al Oriente. Allí, ante la falta de empleados públicos, los padres recibieron poderes civiles (tales como la administración de justicia) además de religiosos. Estas facultades extra-religiosas, que por cierto nunca fueron descritas en detalle, eran vistas como parte de una coyuntura temporal ${ }^{8}$.

Mapa 1. La misión jesuita en el Alto Napo

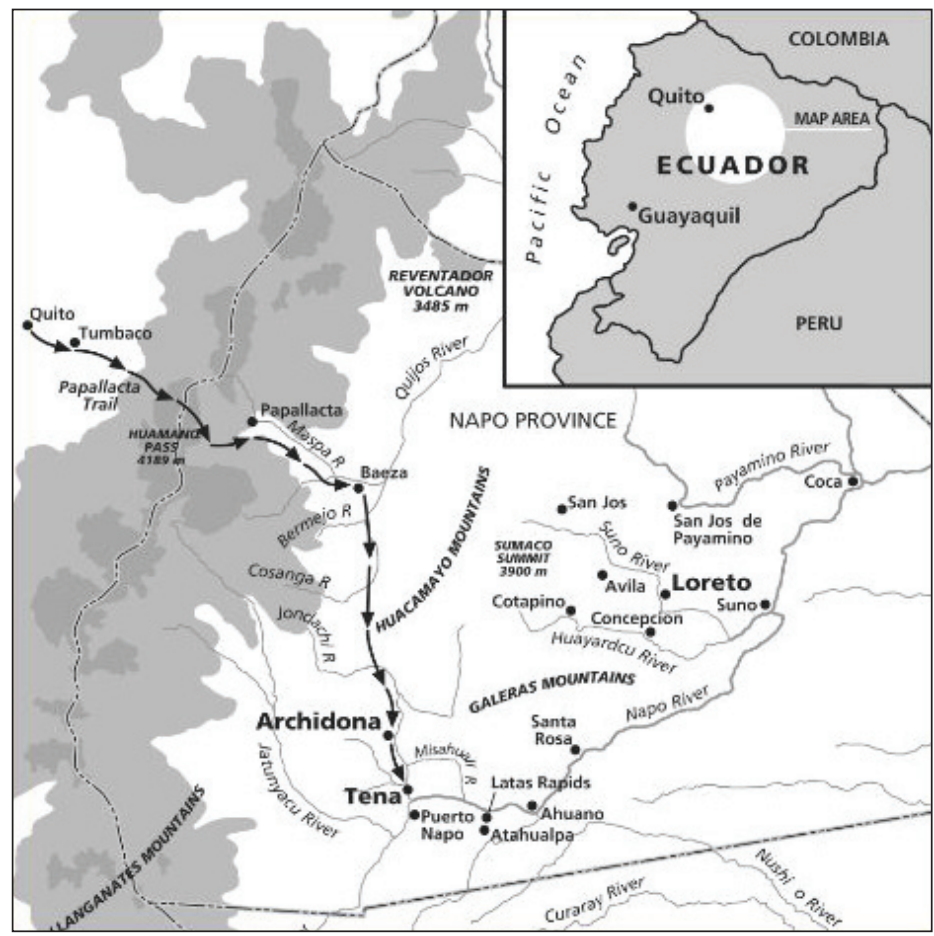

Fuente: Lester Jones sobre un mapa de Muratorio, 1991, p. 19. Se resaltan el Camino de Papallacta y los tres pueblos con presencia misionera semi-permanente.

5 Ver, por ejemplo, Carta de P. de B. (?) al Obispo de Quito. Roma, 24-V-1862. ARSI, Aequat., 1001-III, 8; y Concilium Provinciae Quitense. Quito, 1865. ARSI, Aequat., 1001-IV, 5.

6 De Missione Fluminis Maragnonis Informatio. Quito, 1-V-1866. ARSI, Aequat., 1001-IV, 11.

7 Contractus circa Missionem Orientalem Instaurandum. Quito, 22-XI-1869. ARSI, Aequat., 1001-V, 9.

8 Mensaje presidencial, citado por LóPez SAnvicente, 1894, p. 12. 


\section{ESTRUCTURA DE LA MISIÓN: MISIONEROS E INDIOS}

\subsection{Alcance y demografía}

El trabajo jesuita en el Oriente ecuatoriano a finales del siglo XIX no tuvo lugar en fronteras lejanas e ignotas, como sucediera en época colonial. Por el contrario, la evangelización se limitó al Alto Napo, entre los valles de los ríos Coca y Napo, una región que había sido lenta pero drásticamente colonizada desde mediados del siglo XVI. La idea original era que los misioneros se ocuparan de todo el Amazonas ecuatoriano (o al menos, ya que las fronteras políticas no estaban bien definidas, hasta el límite con el Perú) pero la falta de recursos humanos lo impidió. Entre 1869 y 1896 un total de 19 padres y 13 hermanos trabajaron en el Alto Napo, aunque nunca hubo más de tres padres y otros tantos hermanos asentados a un mismo tiempo en la misión ${ }^{9}$.

El Alto Napo era la única región del Amazonas ecuatoriano que contaba con una red de asentamientos más o menos permanentes. Así, en lugar de crear reducciones a la manera colonial, los jesuitas se adaptaron a esta red y la llamaron "la misión". En 1870, los padres establecieron su base en Archidona. A partir de ahí intentaron expandir su influencia por todo el Alto Napo, aunque sólo consiguieron formar dos centros misionales de relativa importancia: Tena, a diez kilómetros de Archidona en dirección sur, y Loreto, en el interior, a donde se podía llegar en cinco días de viaje (Ver Mapa 1). El resto de los pueblos fue incorporado a la misión mediante un sistema de visitas. En la práctica las visitas fueron selectivas y muy esporádicas: algunos pueblos no vieron jesuitas durante años; además, generalmente las visitas no duraban más de tres o cuatro semanas ${ }^{10}$.

El Alto Napo había permanecido en contacto con los Andes durante siglos, aunque de forma discontinua. La única ruta de acceso a la región desde Quito era el escabroso camino de Papallacta, 150 kilómetros que, en las vertientes orientales de los Andes, sólo podían cubrirse a pie. Los asentamientos, llamados "pueblos", eran en verdad caseríos: claros en el bosque con dos o tres cabañas. La población más o menos estable de cada pueblo incluía, típicamente, una o dos familias de comerciantes y a veces un gobernador ${ }^{11}$, el resto eran mercaderes itinerantes. Aunque en teoría la población no indígena no pertenecía a la misión, en la práctica, como veremos en la siguiente sección, los comerciantes convivieron con los padres. En cuanto a los indios, estos vivían en los alrededores de cada pueblo, en sus residencias tradicionales o carutambos, a uno o dos días de camino por la selva. Los jesuitas intentaron que los indios se establecieran permanentemente dentro de los pueblos, y aunque consiguieran victorias parciales, en general fracasaron. En otras palabras, la misión fue sobre todo un

9 Para más información sobre personal y divisiones administrativas entre 1869 y 1896, ver los Catálogos editados y existentes en el ARSI: COMPAÑÍA, 1870-97.

10 También en 1888 se crearía en Ecuador la Provincia del Buen Pastor y, además de su establecimiento en Archidona, esto resultó en la apertura de colegios en Quito y Guaranda. Las primeras hermanas del Buen Pastor en llegar al Alto Napo fueron María de Loreto Crilly, Madre Superior, María de San Augusto Gil, María de Teresa Velasco y María de Santa Julia Zamora. Ver Miranda Rivadeneira, 1974, p. 111.

11 La visión más completa del Alto Napo en los años previos a la llegada de los Jesuitas está en VILLAVICENCIO, 1984. 
régimen voluntario que dependía de la voluntad de los indígenas para abandonar el bosque y acudir a la iglesia.

El número total de Napo Runa al que los padres tenían acceso se puede conocer de manera aproximada. A finales de la década de 1880, el número de indios de misión (todos ellos Napo Runa) se calculó en unos 6.000. Los padres obtenían esta información durante sus visitas pastorales, bien contando individuos (o "indios") o "familias" nucleares (o "matrimonios" o "vecinos"; cada vecino era el pater familias), cada una de tres o cuatro miembros (Ver Cuadro 1). Sin embargo, hay que anotar de nuevo que esta era una población flotante y que en la práctica sólo un puñado de escolares y casi ningún adulto residían en la misión permanentemente ${ }^{12}$.

Cuadro 1. Habitantes de los pueblos del Alto Napo entre 1884 y 1894

\begin{tabular}{|l|c|c|c|c|c|}
\hline Pueblos & $\begin{array}{c}\mathbf{1 8 8 4} \\
\text { vecinos }\end{array}$ & $\begin{array}{c}\mathbf{1 8 8 5} \\
\text { indios }\end{array}$ & $\begin{array}{c}\mathbf{1 8 9 1 - 2} \\
\text { familias }\end{array}$ & $\begin{array}{c}\mathbf{1 8 9 3 - 4} \\
\text { matrimonios }\end{array}$ & $\begin{array}{c}\mathbf{1 8 9 4} \\
\text { familias }\end{array}$ \\
\hline Archidona & 348 & 1487 & 458 & 460 & 500 \\
\hline Tena & 125 & 721 & 200 & 183 & 228 \\
\hline Puerto Napo & 83 & 449 & 135 & 110 & 130 \\
\hline Ahuano & 62 & 147 & 37 & 40 & 40 \\
\hline Sta. Rosa & 54 & 80 & 30 & 10 & 15 \\
\hline Suno & 17 & 74 & 24 & 20 & 9 \\
\hline Coca & 10 & 53 & 9 & 10 & -- \\
\hline Payamino & 32 & 101 & 34 & 40 & 38 \\
\hline Cotapino & 16 & 91 & -- & 18 & 26 \\
\hline Concepción & 70 & 662 & 200 & 184 & 200 \\
\hline Loreto & 292 & 1,335 & 400 & 363 & 400 \\
\hline Avila & 81 & 830 & 150 & 229 & 136 \\
\hline San José & 32 & 150 & 125 & 37 & 130 \\
\hline TOTAL & 1,214 & 6,170 & 1,802 & 1,704 & 1,852 \\
\hline
\end{tabular}

Fuentes: 1884: Reducciones o pueblos de la misión de Oriente. "anno incerto" [ca. 1884]. ARSI, Aequat., 1001-XVI, 10/a; 1885: Región oriental, Napo. Oriente, IV-1885. ANHE, Ministerio de Gobierno, Oriente; 1891-2: CÁCERES, 1892, pp. 24-37; 1893-4: LóPEZ SANVICENTE, 1894, p. 74; 1894: Carta de Andrés Justo Pérez al Superior. [Archidona], 26-VII-1894.

ARSI, 1002-IV, 9.

A esto hay que añadir el efecto de las epidemias, que nunca fueron catastróficas pero que golpeaban regularmente la misión, vaciando los pueblos durante meses. La primera epidemia (disentería) apareció en Loreto en mayo de 1874, coincidiendo con el establecimiento de la escuela en ese pueblo, y dejó varios muertos tras de sí $^{13}$. A

12 Un buen ejemplo de este comportamiento lo tenemos en, Carta de Andrés Justo Pérez a Manuel Gil. Archidona, 16-VI-1878. ARSI, Aequat., 1001-XII.

13 Ver Jouanen, 1977, p. 94. 
esta le siguieron las epidemias de 1875, 1890, 1892 y 1896, la más devastadora, ya que alrededor de 300 indígenas perdieron la vida en la región de Puerto Napo ${ }^{14}$.

\subsection{Viejos y niños: política y educación}

Los padres jesuitas contactaban con la mayoría de población Napo Runa a través de las jerarquías socio-políticas que ya existían antes de su llegada. Dentro de la sociedad Napo Runa el poder fluía de manera horizontal. El "curaca" (máxima autoridad indígena) y el "yachaj" (o chamán) eran las figuras más importantes, aunque el liderazgo estaba muy difuminado entre familias nucleares y grupos de residencia y consanguineidad ("muntun") 15 . Los jesuitas quisieron promover entre los indígenas un sistema de rotación de cargos o "varas" similar al que existía en los Andes, y que los Napo Runa también conocían desde época colonial. En la práctica, no obstante, esta estructura política funcionó muy débilmente y sobre todo favoreció la integración Napo Runa. Los misioneros se referían a "los viejos" con los cuales negociaban necesidades específicas, por ejemplo, la reconstrucción del techo del convento o la limpieza de la plaza ${ }^{16}$. En el día a día, los padres contactaban con quien se hallara en ese momento en la vecindad. En cuanto a los indígenas, por un lado consideraban que los padres tenían poderes mágicos similares a los del "yachaj", tales como causar el vómito o incluso la muerte a quienes no asistían a la iglesia; y por otro lado los consideraban nada más que una molestia ${ }^{17}$.

Quizás la actividad jesuítica de mayor repercusión entre los Napo Runa fue la escolarización de los niños. En la mentalidad misional de la época, y tal y como sucediera desde el siglo XVI, se establecía una clara diferencia entre viejos y niños. Los adultos eran a menudo catalogados como casos perdidos, impermeables a la catequesis $^{18}$. Los infantes, en cambio, eran vistos con exagerado optimismo en tanto que "tabula rasa", y así gran parte de los esfuerzos jesuitas fueron dirigidos en esa dirección. No hace falta recordar aquí la importancia dada a la instrucción de menores en la filosofía jesuítica ${ }^{19}$. El currículo de los niños incluía clases en quichua y castellano, gramática española, aritmética, historia religiosa y caligrafía. Además, los niños aprendían carpintería mientras que las niñas, según la costumbre decimonónica, eran instruidas en corte y confección ${ }^{20}$. Para la educación femenina, los jesuitas contaban con la ayuda de varias Madres del Buen Pastor, venidas desde Quito ${ }^{21}$. Durante algún tiempo al menos, niños y niñas vistieron uniforme. Los escolares tenían a su dispo-

14 Carta de Juan Mosquera al Ministro de Estado. Archidona, 24-VI-1890. Archivo Nacional de Historia del Ecuador (en adelante ANHE), Ministerio de Gobierno, Oriente; Carta de Vidal Falconi Robalino al Ministro de lo Interior. Archidona, 22-XI-1892. ANHE, Ministerio de Gobierno, Oriente; Carta de Alejandro Sandoval al Ministro de lo Interior. Archidona, 10-V-1896. ANHE, Ministerio de Gobierno, Oriente.

15 VillaVicencio, 1984, es una buena referencia.

16 Ver, por ejemplo, Andrés Justo Pérez, Breve memoria. Archidona, 12-IV-1877. ARSI, Aequat., 1001XII, 5.

17 La historia oral recogida por Blanca Muratorio así lo indica. Muratorio, 1991, pp. 97, 95.

18 Andrés Justo Pérez, Breve memoria. Archidona, 12-IV-1877. ARSI, Aequat., 1001-XII, 5.

19 Para un estudio contemporáneo, ver Schwickerath, 1903.

20 VASCÓNEZ, 1941, p. 15.

21 Ibídem, p. 15. 
sición plumas, tinta y pizarras y, hacia el final del periodo jesuita, el gobierno central se preocupó de enviar a Archidona algunos textos escolares ${ }^{22}$.

A pesar de que los pensadores de la orden argumentaban que esta era "puramente espiritual" es indiscutible que el objetivo primordial de la educación era práctico ${ }^{23}$. Los niños aprendían a sustentar a los padres y para ello trabajaban diariamente en los huertos (o "chacras") de la misión, mientras que las niñas eran adiestradas para ser esposas y sirvientas. El objetivo último era crear comunidades cristianas estables, en torno a la iglesia y bajo la tutela misional. Además, los intereses jesuitas coincidían con el proyecto de construcción del estado-nación ecuatoriano según Gabriel García Moreno, quien, como ya vimos, había llamado a la orden para que se pusiera al frente de colegios y universidades ${ }^{24}$. En el Oriente también la educación era vista como la llave que abría la puerta de la "civilización," un concepto que en el siglo XIX se asociaba a valores burgueses concretos: "decencia", "moralidad", "bienestar doméstico" etc. ${ }^{25}$.

Ya hacia 1870 los jesuitas acordaron con los "viejos" que los adultos asistirían a misa al menos los domingos, mientras que niños y niñas lo harían diariamente ${ }^{26}$. Esto implicaba que los niños no podrían residir a una larga distancia de los pueblos, y favorecía la creación de internados. Una escuela para niños, muchos de los cuales pasaban la noche en el convento, funcionaba en Archidona desde 1870-71. En 1875 había cuatro escuelas en el Alto Napo: dos en Archidona educaban a 217 niños y 100 niñas respectivamente; una escuela para niños en Loreto y otra en Puerto Napo, a la que los jesuitas consiguieron atraer 72 niños Napo Runa ${ }^{27}$. Las escuelas funcionaron de manera intermitente hasta 1896, principalmente debido a las epidemias y, como veremos, la falta de financiación por parte del gobierno central. En su momento álgido, según las estimaciones de los misioneros, el sistema escolar del Alto Napo incluía 1.462 estudiantes, 838 niños y 624 niñas ${ }^{28}$. El número de estudiantes, sin embargo, variaba ostensiblemente de un día para otro ${ }^{29}$.

La obediencia era un valor jesuita que combinaba la observancia de una larga lista de reglas con el castigo físico. El reglamento de los internos de Archidona, por ejemplo, estipulaba que los niños debían levantarse a las cinco para acudir a misa a las cinco y media, desayunar a las seis, trabajar en la chacra de la misión, acudir a clases hasta las once y media, y un largo etcétera que ocupaba la totalidad del día ${ }^{30}$. No cabe la menor duda de que este era el ideal; como hemos visto, la estabilidad de la misión era precaria. Una forma de corrección de las faltas eran los latigazos. Según la regla jesuita, que concernía tanto a los colegios europeos como a las misiones de frontera,

\footnotetext{
22 Ver, por ejemplo, Carta de Juan Mosquera al Ministro de Estado. Archidona, 14-XI-1889. ANHE, Ministerio de Gobierno, Oriente.

23 Schwickerath, 1903, p. 76.

24 Ver Ayala Mora - Cordero Agullar, 1994, p. 222.

25 Una idea general de la mentalidad burguesa en el Quito de fin de siglo la ofrece KingMAN GARCÉs, 2006.

26 Andrés Justo Pérez, Breve memoria. Archidona, 12-IV-1877. ARSI, Aequat., 1001-XII, 5.

27 VASCÓNEZ, 1941, p. 9.

28 Ibídem, p. 15.

29 Gaspar Tovía, Informe. Archidona, 1890. ARSI, Aequat., 1002-II, 2.

30 Reglamento de los internos de Archidona. Archidona, 1894. ARSI, Aequat., 1002-IV, 8.
} 
tal método sólo debía aplicarse in extremis ${ }^{31}$. Los padres del Alto Napo, sin embargo, caían con frecuencia en el uso del látigo, algo que en privado lamentaban. Se podría decir que la violencia demostraba la frustración de los misioneros con el progreso de la misión. Según la documentación, es más que probable que, por motivo de la crueldad de uno o dos padres, en el Napo los castigos se aplicaran con más severidad que en otras misiones jesuitas ${ }^{32}$.

\subsection{De la escuela a la fábrica: economía}

La misión jesuita se nutría de dos tipos de fuentes económicas: internas y externas, o amazónicas y no amazónicas. Las fuentes externas eran también dos: por un lado el gobierno ecuatoriano y por otro el resto de benefactores con quienes la Compañía contactaba independientemente. Es necesario insistir en el hecho de que el gobierno ecuatoriano apenas si apoyó a la misión jesuita en el Oriente. De los 11.000 anuales pesos prometidos (para ser recaudados de otras órdenes religiosas, iglesias etc.) una mínima parte llegó a manos de los misioneros, y sólo una vez, el primer año de la mi$\operatorname{sión}^{33}$. En cuanto a las fuentes de ingresos independientes, los jesuitas contaban con el apoyo logístico de una densa red internacional de colegios y procuras. Ante la falta de financiación por parte del gobierno ecuatoriano, esta red a menudo constituía la única fuente de ingresos de la misión ${ }^{34}$. El dinero en sí mismo, por supuesto, no servía de mucho en el Oriente, salvo para comprar mercancías en Quito. Internamente, la misión de nutría de una serie de arreglos informales e irregulares que daban fe, una vez más, de su precario estado ${ }^{35}$.

La única fuente de ingresos más o menos segura de la misión eran los mismos indígenas. Tras su llegada al Oriente los jesuitas continuaron con la antigua tradición de los "camaricos", esto es, el pago en especie de bodas y fiestas. Los padres intentaron controlar e institucionalizar esta práctica y, aunque sólo lo consiguieron en parte, los camaricos se cobraron con mayor o menor regularidad. Así, cuando visitaban los pueblos, o en Tena y Archidona, los misioneros aprovechaban para celebrar matrimonios y para "autorizar" la celebración de fiestas, y a cambio recibían una cantidad predeterminada de gallinas, huevos o pita (un tipo de fibra), o de oro en polvo. Tal y como habían hecho antes otros viajeros y autoridades, los jesuitas distinguían entre pueblos piteros, que se encontraban hacia el interior en la zona de Loreto, y pueblos oreros, que estaban localizados cerca de los ríos, de cuyas playas se podían extraer pequeñas cantidades de este material ${ }^{36}$. La moneda de cambio oficiosa en el Oriente era, desde tiempos coloniales, el lienzo. Este material era muy querido por los indígenas, que lo usaban como ponchos, especialmente antes de la introducción de camisas y panta-

\footnotetext{
31 Ver SCHWiCKerath, 1903, pp. 614-619.

32 Carta de Antonio Salazar a Luis Martín. Loreto, 10-I-1895. ARSI, Aequat., 1002-V, 3.

33 Decreto-contrato sobre las misiones del Oriente. Quito, 22-II-1869. ARSI, Aequat., 1001-V, 10; ver también, Bases para la contrata de la misión del Marañón. Quito, 25-XI-1869. ARSI Aequat, 1001-V, 2.

34 Carta de Gaspar Tovía al R.P. Asistente. Quito, 16-VII-1891. ANHE, Ministerio de Gobierno, Oriente.

35 Ver, por ejemplo, Carta de Antonio Llori al Ministro de Estado etc. Ahuano, 24-III-1883. ANHE, Ministerio de Gobierno, Oriente.

36 Andrés Justo Pérez al Asistente de España. Archidona, 16-VI-1878. ARSI, Aequat., 1001-XII, 2.
} 
lones en el Alto Napo a principios del siglo XX. El lienzo se compraba en Quito en varas para ser distribuido luego entre los indios a cambio de horas de trabajo o tareas determinadas ${ }^{37}$. Además, no sólo los niños internos sino también un número limitado de Napo Runa (tres o cuatro familias, a lo sumo) residían en o cerca de Tena y Archidona de forma más o menos permanente, y cuidaban de chacras, gallinas etc. ${ }^{38}$.

\section{LOS EVENTOS: RUMOR, POLÍTICA Y CAÍDA DE LA MISIÓN}

\subsection{Comerciantes e indígenas, 1870-1875}

Los pocos mercaderes en el Alto Napo, ya fuera residentes en la región o itinerantes, tuvieron un efecto negativo en la misión. Desde antes de su llegada al Oriente, gracias al viaje de Monseñor Pastor en 1866, citado más arriba, los jesuitas estaban al corriente de las relaciones de crédito forzosas ("ventas forzadas" o "repartos") de los comerciantes con los Napo Runa. En su informe de 1866, Monseñor Pastor condenó estas prácticas y se refirió a la crueldad con la que los blancos trataban a los indígenas, mencionando explícitamente al colombiano Faustino Lemos Rayo, recordado en la historia ecuatoriana por tomar parte activa en el asesinato del presidente Gabriel García Moreno en $1875^{39}$. Los primeros jesuitas en el Oriente, los padres Ambrosio Fonseca y Manuel Guzmán, obtuvieron permiso del presidente para prohibir el comercio crediticio, sin hacer ninguna distinción entre ventas forzadas y ventas al fiado. Este decreto tuvo como consecuencia un intento de rebelión indígena, fomentada precisamente por Rayo ${ }^{40}$. Como resultado, los padres regresaron a Quito y la misión fue desmantelada durante seis semanas. En enero de 1872 Andrés Justo Pérez llegó a Archidona con un programa más flexible que el de sus antecesores. Así, Justo Pérez prohibió sólo las ventas forzadas - permitió el crédito voluntario- y se preocupó de acomodar las necesidades de la misión a las prácticas económicas existentes. Por ejemplo, los jesuitas adoptaron el sistema de camaricos, previamente considerado inmoral ${ }^{41}$.

\subsection{En Quito: el gobierno, la iglesia y los jesuitas, $\mathbf{1 8 7 5 - 1 8 9 0}$}

Poco después de la crisis de Archidona, el 6 de agosto de 1875, el presidente Gabriel García Moreno, máximo protector de la misión, era asesinado en Quito. Tal y como escribiera el padre Pérez, en 1873 o 1874 dos familias andinas, los Peña y los Cañadas, habían llegado a un acuerdo con el gobierno central para la venta de cascarilla oriental por un valor de 600 pesos anuales. El agente principal de este contrato era Rafael Abarca, quien se había establecido en Archidona con la intención de aprove-

37 Cada vara equivalía a unos 80 centímetros.

38 López Sanvicente, 1894, pp. 42-43.

39 De missione fluminis Maragnonis informatio. Quito, 1-VI-1866. ARSI, Aequat., 1001-IV, 11.

40 Loor, 1955, p. 162; JoUANEN, 1977, pp. 34-35, 80.

41 Andrés Justo Pérez, Breve memoria. Archidona, 12-IV-1877. ARSI, Aequat., 1001-XII, 5. 
char el trabajo misional para reclutar mano de obra indígena ${ }^{42}$. Es importante insistir aquí en que los jesuitas no sólo tenían poderes civiles y legales sobre los comerciantes, sino que en el Ecuador de finales del siglo XIX también contaban con amplia autoridad moral. Cuando el padre Pérez ordenó a Abarca abandonar el Oriente para dar cuenta de su errático comportamiento ante las autoridades de Quito, el comerciante acudió a la capital voluntariamente y sin escolta. Algo similar sucedió con Faustino Lemos Rayo. Conocido en el gobierno ecuatoriano por el destacado papel que desempeñó en los conflictos armados de la década de 1850, como hemos visto, hacia 1870 su reputación había caído en picado ${ }^{43}$. Parece que tras uno de sus enfrentamientos con los jesuitas orientales, Rayo recibió la orden de viajar a Quito, donde se entrevistó con García Moreno. Es posible que el presidente prohibiera a Rayo regresar al Oriente, lo cual dañaba sus intereses comerciales, y que este fuera el motivo que impulsó al colombiano a unirse a la conspiración que desembocó en el famoso "tiranicidio".

La Compañía de Jesús en Ecuador reaccionó al deceso de García Moreno con inmediatez. Entre noviembre y diciembre de 1875 varios jesuitas establecidos en Quito y Guayaquil decidieron regresar a Europa ${ }^{44}$. Mientras tanto, tras meses de debate en el Congreso, Antonio Borrero fue elegido presidente. A pesar de que la posición del nuevo líder era conciliadora y hasta favorable a la Compañía, la desbandada continuó. Tan pronto como Borrero llegó al poder, el padre Francisco de San Román, entonces Superior de los jesuitas en Ecuador, anunció que los profesores de la Escuela Politécnica abandonarían el país al cierre del año escolar. Borrero llegó a escribir a Pio IX, a quien solicitó sin éxito la revocación de esta decisión ${ }^{45}$. Los liberales ecuatorianos, cada año más fortalecidos por el crecimiento de la economía del cacao, aceptaron al nuevo presidente quien, entre otras medidas, relajó la estricta censura de prensa impuesta por García Moreno. No obstante, Borrero se mantuvo fiel al bando conservador y se negó a tomar medidas liberales, ni siquiera de manera simbólica. Por este motivo, a finales de 1877 fue depuesto en un golpe militar orquestado por los liberales de Guayaquil. El siguiente en la línea de sucesión presidencial fue el General Ignacio de Veintimilla, cuya dedicación a la causa liberal era en principio incuestionable ${ }^{46}$. Las tensiones crecieron cuando en marzo de 1877 el Arzobispo de Quito, Monseñor Checa, fue envenenado durante la misa del Viernes Santo ${ }^{47}$. Ante la oposición popular, Veintimilla suavizaría su política anti-clerical, aunque la decisión de ser nombrado Jefe Supremo, sinónimo de dictador militar, le enfrentó tanto a liberales como a conservadores. La resistencia armada no tardó en aparecer en la costa (Manabí y Esmeraldas) y entre los militares exilados en Perú. Serían estos últimos quienes a finales de 1883 tomaran el poder en Quito y pusieran fin al gobierno de Veintimilla.

42 Ibídem.

43 Ibídem. Ver también Carta de Venancio Rueda al Ministro de Relaciones Exteriores del Ecuador. Quito, 17-VIII-1875. Archivo del Ministerio de Relaciones Exteriores del Ecuador (AMRE en adelante), B.8.3.

44 Bustos - Videla, 1966, p. 224.

45 Ibídem, pp. 226-227.

46 Ibídem, pp. 230-231.

47 Para una descripción contemporánea de estos eventos poco conocida ver CoRAL, 1899, pp. 36-38. 
La transición progresista siguió a este periodo, bajo el gobierno de José María Caamaño (1884-1888). ¿Cuáles fueron las relaciones entre iglesia y estado, entre jesuitas y el gobierno, en esta época incierta? Parece que, mientras la iglesia secular perdió privilegios de forma escalonada, la Compañía de Jesús alcanzó cierta estabilidad, si bien a cambio de una posición marginal en el ámbito de la política ${ }^{48}$. En 1885 se publicó la Ley Especial de Oriente, prueba de la expansión del estado-nación ${ }^{49}$. Aunque a la misión se le seguía otorgando una función preponderante, para todos los efectos prácticos la Ley de Oriente era un código de gobierno civil, según el cual la separación entre iglesia y estado quedaba implícitamente establecida. Con el mismo objeto, en 1888 la nueva administración de Antonio Flores (1888-1892) decidió dividir el Oriente en cuatro vicariatos: Napo, Canelos, Macas y Gualaquiza. De estos, sólo el primero -es decir, el Alto Napo- sería encargado a la Compañía ${ }^{50}$. Desde el punto de vista jesuita, esta medida era una prueba más de la existencia de una atmósfera hostil en Quito. Las acusaciones tradicionales (secretismo, crueldad, ineficacia) de hecho ya circulaban por la capital y aunque tenían cierta verdad (sobre todo en lo que respecta a su crueldad para con los indígenas) no carecían de intriga e imaginación.

\subsection{En el Oriente: el poder civil y el poder religioso}

Los máximos responsables de alimentar el anti-jesuitismo en el Ecuador de finales del XIX fueron las autoridades civiles del Oriente. La Ley Especial de 1885 había creado una situación contradictoria: por una parte, los poderes civiles dados a los jesuitas en 1870, tales como el monopolio sobre la educación, no habían sido oficialmente revocados; por otra parte, la Ley Especial exhortaba a los oficiales quiteños a extender su jurisdicción hacia la frontera oriental ${ }^{51}$. Estos veían a la misión como una institución religiosa cuyas actividades debían limitarse a la celebración del calendario católico. Sobra decir que el poder civil en el Oriente era muy débil y que a menudo los enviados de Quito carecían del más mínimo apoyo material por parte del gobierno central. Entre 1885 y 1910 no había en Archidona y Tena más de tres o cuatro oficiales y dos o tres soldados a un mismo tiempo, y estos no contaban con el armamento, los uniformes, los medios de transporte o los sueldos regulares que la ley prometía ${ }^{52}$. A pesar de todo, las autoridades se veían a sí mismas como representantes legítimas del gobierno central y este, si bien brillaba por su ausencia, al menos de forma tácita amparaba a sus enviados en la frontera.

48 Evidencia de este acercamiento regional fue la extensión de la línea telegráfica entre Quito y Guayaquil.

49 Reglamento para la Provincia Oriental. Quito, 21-VI-1885. Archivo de la Biblioteca de la Función Legislativa (ABFL en adelante), 1885. Ver también ANDRADE MARín, 1884.

50 Erección de Vicariatos Apostólicos en el Oriente. Quito, 11-VIII-1888. ABFL, 1888. Los dominicos se establecerían en Canelos y, años más tarde, los franciscanos y salesianos en Gualaquiza y Macas respectivamente. Finalmente, también en 1888, Antonio Flores accedió a las súpicas jesuitas y decidió enviar a la orden de las Madres del Buen Pastor al Oriente para hacerse cargo de la educación de las niñas. MiRANDA RIVADENEIRA, 1974, pp. 111.

51 Un comentario sobre esta paradoja en, Carta de Gaspar Tovía al General. Archidona, 5-XI-1887. ARSI, Aequat., 1001-XVI, 10.

52 Un esquema administrativo del Alto Napo en el momento de la expulsión jesuita lo ofrece HurTado, 1897, p. 15. 
Uno de los primeros oficiales en levantar la voz contra los jesuitas en el Oriente fue el gobernador Antonio Estupiñán (1889-1890). Poco después de su nombramiento, antes incluso de partir hacia la selva, Estupiñán se dirigió al gobierno central para suscribir el rumor de que los padres orientales ponían obstáculos al comercio a la vez que se afanaban ellos mismos en actividades mercantiles ${ }^{53}$. Según los informes jesuitas, al llegar al Oriente, Estupiñán no sólo evitó reunirse con los padres, sino que se dedicó a viajar por la región recogiendo informes en contra de la misión ${ }^{54}$. El gobernador se interesó especialmente por la cuestión educativa, dominio tradicional de la iglesia sobre el cual el estado ecuatoriano comenzaba a ganar terreno ${ }^{55}$. Así, la opinión general era que en última instancia las autoridades civiles representaban al Ministerio de Instrucción Pública, creado en 1884, y a cuyas órdenes los jesuitas debían someterse. Según Estupiñán, el objetivo prioritario de la educación misional no era la integración indígena en la sociedad nacional sino su aislamiento ${ }^{56}$. Ante estas acusaciones el padre Tovía respondió que, tras la muerte de García Moreno, ninguna de las autoridades civiles en el Oriente se había preocupado por atraer los niños a la escuela, ya que sus únicas aspiraciones eran precisamente comerciales ${ }^{57}$.

\subsection{Los nuevos mercaderes y la población indígena}

La expansión del estado nacional no era el único motivo de preocupación entre los misioneros. Hacia finales del siglo XIX, la economía amazónica creció a un ritmo vertiginoso gracias al boom cauchero. El gobierno ecuatoriano quedó excluido de los beneficios de la goma, y el Alto Napo era una región pobre y distante incluso para los mercaderes de la Alta Amazonía. Sin embargo el tráfico comercial afectó en profundidad, directa o indirectamente, a toda la cuenca. Hacia principios de la década de 1890 Iquitos, ciudad peruana en el Marañón, era el motor económico de la región. El efecto centrípeto de Iquitos sobre el cercano río Napo fue inevitable ${ }^{58}$. Unas tres decenas de colonos, sobre todo peruanos, se asentaron en el bajo y medio Napo en la década de $1890^{59}$. Aunque las dificultades de navegar a vapor en la parte alta del río amortiguaran el impacto, los abusos contra la población indígena incrementaron notablemente en este periodo. En efecto, rumores de "correrías" (esto es, búsqueda y captura de mano de obra) en la ribera sur del Alto Napo circulaban de forma ocasional ${ }^{60}$.

53 Carta de Antonio Estupiñán al Ministro de lo Interior. Quito, 13-XI-1889. ANHE, Ministerio de Gobierno, Oriente.

54 Gaspar Tovía, Informe al Ministerio de lo Interior. Archidona, 1892. ARSI, Aequat 1002-II, 2.

55 Véase Bustos - Videla, 1966.

56 Antonio Estupiñán, Informe. Concepción, 29-I-1890. ANHE, Ministerio de Gobierno, Oriente.

57 Ibídem.

58 A través del Napo se accedía al relativamente próspero Curaray, y también al Putumayo, a través del Aguarico.

59 Esta información fue obtenida por un oficial peruano. Ver FUENTES, 1908, p. 172.

60 Para un estudio de las relaciones laborales en la baja Amazonia, ver SANTos, 1980, p. 66 y MurATORIO, 1991. 
Los jesuitas fueron testigos de los albores de este proceso y lo denunciaron repetidamente ante las autoridades de Quito. En 1890 el gobierno ecuatoriano ordenó a los indígenas que no pagasen sus deudas, al tiempo que pedía la creación de un censo de comerciantes en las riveras del Napo. Según el documento que siguió a esta orden, un total de 12 comerciantes vivían entre Archidona y $\mathrm{Coca}^{61}$. El más importante era Javier Morán, el único colono blanco en el pueblo de Coca. Tras su visita de 1887, el jesuita Rafael Cáceres anotó la decadencia de este pueblo: 20 años atrás había tenido 40 familias Napo Runa y para aquel entonces sólo tenía nueve ${ }^{62}$. Morán, según se sobreentendía de los comentarios de Cáceres, habría movilizado a los Napo Runa río abajo. El jesuita obtuvo permiso del gobierno para ordenar a Morán y el resto de familias Napo Runa en Coca a dejar el pueblo para establecerse en Suno. Morán, sin embargo, desoyó esta orden y continuó desafiando a los jesuitas. En 1888, durante su visita a Coca, el padre Manuel Puertas fue golpeado por dos de los peones de Morán. Este incidente resultó en el arresto de los peones y su encarcelamiento en Quito. Uno de ellos murió poco después; el otro, un Napo Runa llamado José Llicuy, fue liberado tras una reunión entre Morán y las autoridades de la capital ${ }^{63}$.

$\mathrm{Al}$ apoyo del gobierno a los comerciantes en detrimento de los jesuitas se unió el hecho de que los indios habían comenzado a desafiar abiertamente el poder de la misión. Desde 1889 los Napo Runa viajaban a Quito para denunciar los abusos cometidos por los padres. Tradicionalmente, los indígenas del Alto Napo habían sido porteadores y guías a lo largo del escabroso camino de Papallacta. Ahora llegaban a la capital en comisiones de tres o cuatro hombres con objetivos concretos. Entre 1889 y 1892 al menos cinco de estas comisiones, provenientes de Archidona, Tena, Ávila y Loreto, fueron recibidas por las autoridades quiteñas ${ }^{64}$. La más importante fue, acaso, la compuesta por Manuel Mamallacta, Antonio Chimbo y Bernardo Grefa. Estos tres Napo Runa expusieron sus quejas ante el Senado y en audiencia privada con el presidente Antonio Flores, a quien le mostraron las cicatrices dejadas por el látigo de los padres. Por fin, los Napo Runa solicitaron la sustitución en el Alto Napo de los jesuitas por los Padres de la Merced, entonces establecidos en Quito ${ }^{65}$.

Fue entonces cuando padre Tovía viajó a la capital para defender a la misión. En una carta dirigida al Congreso ecuatoriano, Tovía argumentó, primero, a favor del castigo físico como medida necesaria y explicó, segundo, que el único motivo por el cual los Napo Runa habían solicitado la sustitución de la Compañía de Jesús por los padres mercedarios era porque habían sido presionados y confundidos por los blancos del Oriente. Según Tovía, a los indios les daría igual qué orden estuviera presente en el Napo, con tal de que "transijiera" con su forma de vida "y les dejaran en paz". Además, Tovía recordó que el hecho de que los jesuitas eran en su mayoría extranjeros causaba resentimiento y que, al contrario, los mercedarios eran en su totalidad

61 Vidal Falconi, Nómina de comerciantes. 19-XII-1892. ANHE, Ministerio de Gobierno, Oriente.

62 CÁCEREs, 1892, p. 72.

63 JouANEN, 1977, pp. 149-151.

64 La Libertad Cristiana. Quito, 3-IX-1892.

65 Carta de Gaspar Tovía al Asistente de España. Archidona, 29-I-1891. ARSI, Aequat. 1002-I, 13. 
ecuatorianos. Para concluir, Tovía describió la alianza entre comerciantes e indios como una unión "monstruosa" entre "civilización" y "salvajismo" 66.

\subsection{La revuelta de 1892}

Para 1892 la caída de la misión parecía inminente. Los comerciantes locales habían empezado a organizarse en contra de la misión. Entre los blancos que causaban mayor preocupación se encontraba Nicanor Flor, quien había ejercido como soldado de escolta en Quito y el Napo hasta que a principios de ese año abandonó el ejército. Flor se asentó entonces cerca de Tena, un lugar que sería la cuna de la revuelta de $1892^{67}$. En esa época, varios comerciantes rondaban la casa de Flor. Uno de ellos era Avelino Pinzón, nacido en Quito pero criado en el Oriente, y quien resentía la expansión de todo poder extra-amazónico en el Napo. De hecho Pinzón había sido expulsado varias veces del Oriente y una vez más había regresado a la región en julio de 1892. Otro personaje que preocupaba a los jesuitas era Rafael Abarca, quien había trabajado para el gobierno ecuatoriano en varias funciones administrativas aunque por entonces ejercía sólo de comerciante en la zona de Archidona. Finalmente, Reinaldo Ampudia, sobrino de Flor, residía en la misma casa. Estos cuatro mercaderes aspiraban a entrar en el negocio del caucho y por ello trataban regularmente con otro nombre de baja reputación, el mentado Miguel Morán, de Coca ${ }^{68}$.

A fines de junio de ese año los padres comenzaron a notar que los indios evitaban ir a Archidona con más insistencia de la habitual. Manuel Mamallacta, dicen las crónicas jesuitas, se había encargado de recorrer varios pueblos esparciendo la falsa noticia de que los Padres de la Merced iban a sustituir pronto a los jesuitas ${ }^{69}$. Sólo 15 ó 20 adultos asistían a la misa dominical y el mismo número de niños acudían a la escuela. Por el contrario, la casa de Nicanor Flor era constantemente visitada por los Napo Runa, de tal forma que, durante dos meses, tal y como Tovía escribió, la casa de Flor se convirtió en "un centro de propaganda salvaje"70.

En 1892 el gobernador era Juan Mosquera ${ }^{71}$, quien se veía a sí mismo como un funcionario ejemplar cuya obligación era cooperar con los jesuitas y poner freno a los abusos cometidos por los comerciantes. Entre 1890 y 1892, en funciones policiales, ya había denunciado y arrestado por prácticas ilícitas a Nicanor Flor y Avelino Pinzón $^{72}$. El 23 de julio de 1892 Mosquera regresaba a Archidona desde el Napo. El

\footnotetext{
66 Gaspar Tovía, Informe. Quito, 1892. ARSI, Aequat., 1002-II, 2.

67 Sobre la llegada de Nicanor Flor a la Amazonía, ver, Francisco Andrade Marín, Informe. Atahualpa, 6-I1884. ANHE, Ministerio de Gobierno, Oriente. Ver también, Carta de Gaspar Tovía al Ministro de lo Interior. [Archidona], 1892. ARSI, Aequat., 1002-II, 2.

68 Carta de Gaspar Tovía al Presidente de la República. Quito, 5-XI-1892. ARSI, Aequat., 1002-II, 24.

69 Gaspar Tovía, 1892, p. 12.

70 Carta de Gaspar Tovía al Presidente de la República. 5-XI-1892. ARSI, Aequat. 1002-II, 24.

71 Carta de Juan Mosquera al Ministro de lo Interior. Archidona, 1-IV-1890. ANHE, Ministerio de Gobierno, Oriente; ver también, Carta de Antonio Estupiñán al Ministro de lo Interior. Quito, 30-IV-1890. ANHE, Ministerio de Gobierno, Oriente.

72 Juan Mosquera, Informe. Archidona, 23-V-1890. ANHE, Ministerio de Gobierno, Oriente; Carta de Juan Mosquera al Ministro de lo Interior. Archidona, 15-X-1890. ANHE, Ministerio de Gobierno, Oriente; Juan Mosquera, Informe. Archidona, 1-VI-1892. ANHE, Ministerio de Gobierno, Oriente.
} 
camino pasaba por la casa de Flor, donde se encontraban este y Avelino Pinzón. Por aquel entonces el gobierno central había nombrado a un nuevo gobernador, Ramón Borja, quien aún se encontraba en Quito. Flor y Pinzón insultaron a Mosquera y, con el pretexto de que sabían que ya no era gobernador, llegaron a forcejear con él ${ }^{73}$. El rumor de este incidente se extendió sin falta. La versión de Tovía era crítica con Mosquera. En una carta de 1893, dirigida al nuevo presidente Luis Cordero y publicada en Quito, Tovía afirmó que Mosquera había rendido su rifle sin ofrecer resistencia alguna, porque entre otros motivos tenía "miedo de Flor". En cualquier caso, desde ese momento, como escribiera el jesuita, la autoridad civil del Oriente estaba "moralmente muerta" 74 .

La revuelta se precipitó desde entonces. Tras su encuentro con Flor, Mosquera continuó su viaje y llegó a Archidona horas después. Esa misma noche los dos únicos rifles de propiedad gubernamental, dos Remington, fueron sustraídos, lo cual no hizo sino azuzar el miedo entre los religiosos. Esa tarde Flor visitó a Mosquera en su residencia de Archidona y los dos fueron vistos charlando amigablemente durante horas. El plan, siempre según los jesuitas, era neutralizar pacíficamente no sólo a los padres sino también a los poderes civil y militar de Archidona para luego tomar Loreto por la fuerza ${ }^{75}$. Así, al día siguiente Reinaldo Ampudia y Avelino Pinzón partieron hacia Loreto. Mientras, Reinaldo Flor permanecía en Archidona, donde reinaba una tensa calma. Los rebeldes llegaron a Loreto el 3 de agosto, según parece respaldados por 70 indígenas locales, y tomaron como prisioneros a dos padres y un teniente político. Dicen las fuentes jesuitas que iban a ser enviados a Coca, donde Javier Morán se encargaría de organizar su martirio. Sin embargo, probablemente porque los indígenas que les conducían decidieron desentenderse de unos y otros, los tres presos fueron abandonados a medio camino, a orillas del río $\mathrm{Suno}^{76}$.

Tras varios días de celebración en Loreto, los rebeldes tomaron rumbo a Archidona para dar el golpe definitivo a la misión. El 6 de septiembre, los jesuitas de Archidona recibieron una carta de Antonio Llori, residente de Ahuano y uno de los pocos blancos que apoyaban siempre a la misión. Llori explicaba sin detalles lo acontecido en Loreto y añadía que podía haber víctimas religiosas. A raíz de esta carta, el padre Tovía decidió enviar al padre Salazar junto con todos los escolares que pudieron reunir a Quito ${ }^{77}$. Coincidió que el nuevo gobernador, Ramón Borja, había salido unos días antes hacia el Oriente con una pequeña escolta militar. Salazar y Borja se encontraron en el camino de Papallacta y juntos se dirigieron a Archidona, a donde llegaron el 10 de septiembre. El único miembro de la revuelta que se encontraba allí era Nicanor Flor, quien fue arrestado inmediatamente ${ }^{78}$. El resto de los rebeldes supieron de la

73 Juan Mosquera, Informe. Archidona, 1-VIII-1892. ANHE, Ministerio de Gobierno, Oriente.

74 Gaspar Tovía, 1892, pp. 15-16, 19.

75 Entonces, Loreto era un pueblo de 200 familias y residencia más o menos fija de varios misioneros y oficiales.

76 La revuelta aparece descrita con mucho más detalle en Gaspar Tovía, 1892.

77 El padre Salazar llevaba consigo una copia de la carta de Llori, transcrita por Mosquera, que llamaba a la adopción de medidas extraordinarias. Carta de Juan Mosquera al Ministro de lo Interior. Archidona, 6-IX1892. ANHE, Ministerio de Gobierno, Oriente.

78 Carta de Ramón Borja al Ministro de lo Interior. Archidona, 14-IX-1892. ANHE, Ministerio de Gobierno, Oriente. 
llegada de Borja en el camino entre Loreto y Archidona y se dispersaron al instante. Durante el mes que siguió a la revuelta, dos o tres líderes indígenas fueron condenados a azotes, mientras que Archidona y Loreto volvieron a una relativa normalidad ${ }^{79}$.

\subsection{Consecuencias y revolución}

Los padres sabían que los Napo Runa habían participado en la conspiración de forma voluntaria, aunque oficialmente culparan a la astucia de los blancos y a la inocencia indígena de lo ocurrido ${ }^{80}$. En su carta pública al presidente Cordero, el padre Tovía reconoció que blancos e indios habían tenido sus propios motivos para tomar parte en la rebelión. Los blancos, según Tovía, deseaban vivir sin ley ni impedimentos de ningún tipo, ya fueran estos el estado o los misioneros. Los indios, en palabras del jesuita, querían seguir viviendo como "salvajes" y no tener nada que ver con la "civilización cristiana". A esto, Tovía añadió, se sumaban la "debilidad e inercia" del gobernador Mosquera, la circulación de "mentiras" en Quito y la "seducción" de los indígenas. No obstante, Tovía reconoció la pronta y efectiva respuesta del gobierno, lo cual no puede sino ser interpretado como un intento de permanecer del lado del nuevo presidente ${ }^{81}$.

En efecto, para entonces el gobierno central miraba con sospechas a la misión. Los rumores y la verdad se mezclaban creando las condiciones ideales para su expulsión. Además la situación política en Quito comenzaba a evolucionar en dirección opuesta a los intereses de los jesuitas. En los primeros años de la década de 1880, el general Eloy Alfaro había iniciado su famosa montonera en la costa en contra de la doctrina conservadora en Quito. El desafío de Alfaro continuó incluso tras el triunfo del progresismo. Paralelamente en Guayaquil los beneficios del cacao (Ecuador era entonces el principal exportador mundial) fortalecían a la clase mercantil, estandarte del liberalismo. En junio de 1895 un alzamiento popular en esta ciudad marcó el comienzo de la Revolución Liberal ${ }^{82}$.

En el Oriente, los ecos revolucionarios llegaron pronto. Pocas semanas después del golpe de Alfaro, a finales de junio de 1895, un pequeño número de comerciantes tomó el convento jesuita en Archidona, y amenazó a también a las dos madres del Buen Pastor que estaban allí entonces. Este incidente resultó en intercambios violentos, inclusive un comerciante muerto por un rifle jesuita, y la noticia alcanzó Quito al poco tiempo ${ }^{83}$. Unos días después las madres del Buen Pastor abandonaron la misión permanentemente y regresaron a la capital, según las crónicas de la época llevando consigo a 46 niñas indígenas ${ }^{84}$. En octubre de 1895 el padre Sanvicente apuntaba que el gobierno central buscaba un gobernador civil idóneo para sustituir a los jesuitas

79 Carta de Ramón Borja al Ministro de lo Interior. Archidona, 17-X-1892. ANHE, Ministerio de Gobierno, Oriente.

80 Ver, por ejemplo, el argumento esgrimido en LóPEz SANVICENTE, 1894, p. 70.

81 Gaspar Tovía, 1892, pp. 53-54.

82 Un resumen de historia política se puede encontrar en AYALA MORA, 1999, pp. 75-91.

83 Carta de Luis Mejicanos al Superior. Archidona, 19-VI-1895. ARSI, Aequat. 1002-V, 18.

84 García, 1985, p. 237. 
en la región Oriental ${ }^{85}$. También desde principios de 1896 una epidemia de viruelas atacó la región: dejó 300 muertos y provocó la huida de los indígenas a sus carutambos del bosque durante meses ${ }^{86}$. En agosto Archidona fue abandonada y los últimos tres jesuitas del Oriente tomaron rumbo a Loreto con todos los niños que pudieron retener. Por fin, el 18 de septiembre de 1896 el nuevo gobernador Alejandro Sandoval recibió una nota de Quito ordenando a los padres que abandonaran la región amazónica en el plazo máximo de cuatro días ${ }^{87}$.

\section{CONCLUSIONES}

El destino de la misión jesuita fue producto de su debilidad interna y de la falta de apoyo gubernamental, en una época de avance del liberalismo. Los mayores problemas internos se debieron al hecho de que los padres no crearon reducciones aisladas, sino que por motivos prácticos se establecieron en los "pueblos" ya existentes. A cambio de la cercanía indígena, los jesuitas tuvieron que lidiar con una larga tradición socio-económica, basada en las relaciones de crédito entre pequeños comerciantes y Napo Runa. A esto hay que añadirle la intensificación del tráfico comercial a finales del XIX, durante el boom cauchero. Casi todo, en una palabra, estaba en contra de la misión; y los frecuentes castigos físicos tampoco ayudaron a ganar el favor indígena. El sistema implantado por los padres fue deficiente, aunque no completamente yermo. Las escuelas, por ejemplo, resurgirían a principios del siglo XX sobre el patrón creado por la Compañía. Los jesuitas no regresaron al Napo, pero otras órdenes (como los Josefinos) sí que lo harían a partir de 1920. Su labor también siguió la pauta iniciada a finales del XIX. Las visitas semanales de indígenas al centro de los pueblos (al menos Archidona y Tena) fueron quizás la mayor victoria jesuita: hacia 1900 eran reconocidas como "días de mercado", dedicados también a la instrucción religiosa.

Es de esperar que este texto haya hecho una doble contribución. Principalmente, se presenta como un avance hacia el conocimiento empírico de la frontera oriental ecuatoriana, en particular en lo que se refiere al estudio de la misión jesuita a finales del siglo XIX. La historiografía al respecto es escasa y el camino por recorrer es largo. Mediante el estudio de documentos poco estudiados o no analizados previamente, el texto contribuye al conocimiento documental de las misiones decimonónicas en la Amazonía durante el siglo XIX, un tema que aún no ha recibido la suficiente atención académica; y en particular, el presente estudio es una aportación a la historiografía ecuatoriana. En segundo lugar, este texto busca promover al análisis micro-histórico de las sociedades de frontera. Al hablar desde el punto de vista de la frontera conocemos, por ejemplo, las grandes diferencias que había entre las intenciones jesuitas y su puesta en práctica. También aprendemos que en la historia de la misión hubo multitud de agentes y factores que contribuyeron a su progreso y caída, no sólo la legislación o

85 Carta de Lorenzo López Sanvicente a José Macchi. Archidona, 29-X-1895. ARSI, Aequat., 1002-V, 30.

86 Maurilio Detroux, Relatio de Missione Napensi. Ecuador, I-VI-1897. ARSI, Aequat., 1002-VII, 1.

87 Carta de Alejandro Sandoval a Maurilio Detroux. Archidona, 18-IX-1896. ARSI, Aequat. 1002-VI, 27. 
la política quiteña. Este artículo ha procurado, en fin, dar a conocer modelos alternativos de análisis que no siempre cuentan con el favor de la historiografía dominante.

\section{REFERENCIAS BIBLIOGRÁFICAS}

\section{ARCHIVOS CONSULTADOS}

ABFL - Archivo Biblioteca de la Función Legislativa (Quito)

AGN - Archivo General del Napo (Tena)

ANHE - Archivo Nacional de Historia del Ecuador (Quito)

ARSI - Archivum Romanum Societatis Iesu (Roma).

ANDRADE Marín, Francisco

1884 Leyes para el Oriente. Proyecto de Ley de Régimen Administrativo Interior del Territorio de Oriente. Quito. Imprenta de J.P. Sanz.

Ayala Mora, Enrique - Cordero Aguilar, Rafael

1994 "El periodo garciano: panorama histórico, 1860-1875". En Ayala Mora, Nueva Historia del Ecuado. Vol.7. Época republicana, I. Quito. Grijalbo Corporación Editora Nacional, pp. 197-235.

Bustos-Videla, César

1966 "Church and State: A History of Politico-Ecclesiastical Relations during the Age of Gabriel García Moreno, 1860-1875". Tesis doctoral. Georgetown University. (Inédita)

CÁCEREs, Rafael

1892 La provincia oriental de la república del Ecuador. Quito. Imprenta de la Universidad.

COMPAÑ̃́A DE JESÚS

1870-97 Catalogus Provinciae Castellanae Societatis Iesu. Madrid. Typis Viudae E. Aguado et Filii. [Et al.]

Coral, Luciano

1899 El Ecuador y el Vaticano o la revolución religiosa en el Ecuador. Guayaquil. Imprenta de El Tiempo.

FUENTES, Hildrebrando

1908 Loreto. Apuntes geográficos, estadísticos, políticos y sociales. Tomo II. Lima. Imprenta de la Revista.

GarCía, Lorenzo

1985 Historia de las misiones en la Amazonía ecuatoriana. Quito. Abya-Yala.

GARCía Jordán, Pilar (ed)

1995 La construcción de la Amazonía andina, siglos XIX - XX. Quito. Abya-Yala. HuRTAdo, Enrique T.

1897 Informe que el Gobernador de la Provincia de Oriente Sr. D. Enrique T. Hurtado dirige al Ministerio de lo Interior. Quito. Imprenta de Espejo. 
JoUANEn, José

1977 Los jesuitas y el Oriente ecuatoriano: 1868-1898. Guayaquil. Editorial Arquidiocesana "Justicia y Paz".

KINGMAN GARCÉs, Eduardo

2006 La ciudad y los otros, Quito 1860-1940: higienismo, ornato y policía. Quito. FLACSO - Universitat Rovira y Virgili.

Loor, Wilfrido

1955 García Moreno y sus asesinos. Quito. La Prensa Católica.

1959 Los jesuitas en el Ecuador: su ingreso y expulsión 1850-1852. Quito. La Prensa Católica.

LóPEZ SANVicente, Lorenzo

1894 La misión del Napo. Quito. Imprenta de la Universidad Central.

Miranda Rivadeneira, Francisco

1974 "Las religiosas del Buen Pastor en el Ecuador: rasgos históricos". Instituto Ecuatoriano de Historia Eclesiástica. Quito, nº1, pp. 97-156.

MoReno TEJADA, Jaime

2009 "Formation and Experience of an Amazon Frontier: Mission, State and Market in the Upper Napo Region of Ecuador, 1870-1930". Tesis doctoral. King's College London. Disponible en: http://books.google.co.th/books/about/Formation_and_ Experience_of_an_Amazon_Fr.html?id=eOO6ZwEACAAJ\&redir_esc $=\mathrm{y}$

Muratorio, Blanca

1991 The Life and Times of Grandfather Alonso: Culture and History in the Upper Amazon. New Brunswick - New Jersey. Rutgers University Press.

SANTOS, Roberto

1980 História econômica da Amazonia, 1850-1920. Sao Paulo. TAC.

SiLVA, Erika

1990 "Estado, iglesia e ideología." En Ayala Mora (ed), Nueva Historia del Ecuador. Vol. 8. Quito. Corporación Editora Nacional, pp. 9-44.

Slater, Candace

2002 Entangled Edens: Visions of the Amazon. Berkeley - Los Angeles- London. University of California Press.

SCHWICKERATH, Robert

1903 Jesuit Education: Its History and Principles Viewed in the Light of Modern Educational Practices. St. Louis. B. Herder.

Tovía, Gaspar

1903 Carta del R.P. Gaspar Tovía al Exmo. Sr. Dr. Don Luis Cordero sobre los últimos sucesos de la Provincia Oriental. Quito. Imprenta del Gobierno.

VASCÓNEZ, Flor

1941 Las misiones jesuíticas del Napo en la república del Ecuador. (Inédito, en la Biblioteca Ecuatoriana Aurelio Espinosa Polit. Cotocollao. Quito).

ViLlaVicencio, Manuel

1984 Geografia del Ecuador [1858]. Quito. Corporación Editora Nacional. 